\title{
Preclinical evaluation of safety and potential of black hellebore extracts for cancer treatment
}

\author{
Jennifer E. Felenda', Claudia Turek', Nora Mörbtt ${ }^{2}$, Anja Herrick', Margit B. Müller ${ }^{3}$ and Florian C. Stintzing ${ }^{1 *}$
}

\begin{abstract}
Background: The therapeutic use of Helleborus niger L. is manifold due to its specific phytochemical composition. Two compound groups, the ranunculin derivates including protoanemonin and the steroidal saponins, are also associated with toxicity (genotoxicity, disintegration of membrane structures). Therefore, in vitro investigations were performed on safety aspects of a Helleborus niger aqueous fermented extract (HNE). In addition its therapeutic potential against various cancer cell lines was assessed to gain insight into the respective mechanisms of action.

Methods: To evaluate the safe use of HNE, Ames and hemolytic tests were carried out. Two angiogenesis assays in 2D and 3D design were conducted to assess the anti-angiogenetic potential, for which human umbilical vein endothelial cells (HUVEC) were chosen. A panel of tumor cell lines was used in 2D and 3D proliferation assays as well in the migration- and invasion-assay. All investigations were performed with HNE compared to reference substances. The 2D proliferation assay was additionally performed with isolated compounds of HNE (characteristic steroidal saponins).

Results: HNE did not exhibit any genotoxic potential. Concentrations up to $10 \mu \mathrm{l} / \mathrm{ml}$ were classified as nonhemolytic. HNE exerted anti-angiogenetic effects in HUVEC and anti-proliferative effects in five cancer cell lines, whereas hellebosaponin A and D as well macranthosid I did not show comparable effects neither singly nor in combination. Due to the inherent instability of protoanemonin in isolated form, parallel investigations with protoanemonin could not be performed. HNE $(600-1000 \mu \mathrm{g} / \mathrm{ml})$ inhibited the migration of certain cancer cells by > $80 \%$ such as Caki-2, DLD-1 and SK-N-SH.

Conclusion: HNE exhibit neither genotoxic nor hemolytic potential. The present investigations verify the antiangiogenetic effects on HUVEC, the anti-proliferative effects and migration-inhibiting properties on tumor cells. The lower effect of the relevant steroidal saponins compared to the whole extract underlines the fact that the latter is more effective than a blend of isolated pharmacologically active components.
\end{abstract}

Keywords: Helleborus niger, Ranunculaceae, Saponin, HUVEC, Tumor cell, Non-mutagenic, Anti-cancer, Antiangiogenetic, Anti-proliferative, Hemolytic activity

\footnotetext{
* Correspondence: florian.stintzing@wala.de

${ }^{1}$ Pharmacological and Clinical Research, WALA Heilmittel GmbH, Dorfstr. 1,

73087 Bad Boll, Eckwälden, Germany

Full list of author information is available at the end of the article
}

(c) The Author(s). 2019 Open Access This article is distributed under the terms of the Creative Commons Attribution 4.0 International License (http://creativecommons.org/licenses/by/4.0/), which permits unrestricted use, distribution, and reproduction in any medium, provided you give appropriate credit to the original author(s) and the source, provide a link to the Creative Commons license, and indicate if changes were made. The Creative Commons Public Domain Dedication waiver (http://creativecommons.org/publicdomain/zero/1.0/) applies to the data made available in this article, unless otherwise stated. 


\section{Background}

Black hellebore (Helleborus niger L. (H. niger)), also referred to as Christmas rose, is a perennial herb with a shallow rhizome blossoming during winter. Taxonomically it is grouped with the Ranunculaceae and can be found in the woods in mountain regions including Germany at 400-1800 m above sea level (Fig. 1) [1, 2].

Black hellebore has been used as a remedy since ancient times. Paracelsus (1493-1541) knew about the healing power of the Christmas rose and recommended the leaves for prevention of dementia and the root extract was applied against gouty arthritis and other joint diseases, epilepsy, apoplexy, kidney weakness with edema and gynecological complaints. Samuel Hahnemann (1755-1843) reported $H$. niger as a remedy to treat depression, lethargy and sleepiness. Rudolf Steiner (1829-1910) assumed an anti-tumor activity [3]. Today, a broad pharmacological spectrum is ascribed to Christmas rose because of its multitude of compounds: anti-bacterial, anti-inflammatory, cholesterol- and blood glucose-lowering, neuroprotective, hepatoprotective and immune-modulating effects [2, 4].

Preparations from the complementary medicine portfolio containing black hellebore are used in the concomitant therapy of oncological diseases. Therefore, the aim of the second part of this investigation was to obtain a better understanding of the therapeutic potential of Helleborus niger extract (HNE) in vitro. The main clinical indications are brain tumors and lymphomas [5]. Furthermore $H$. niger is

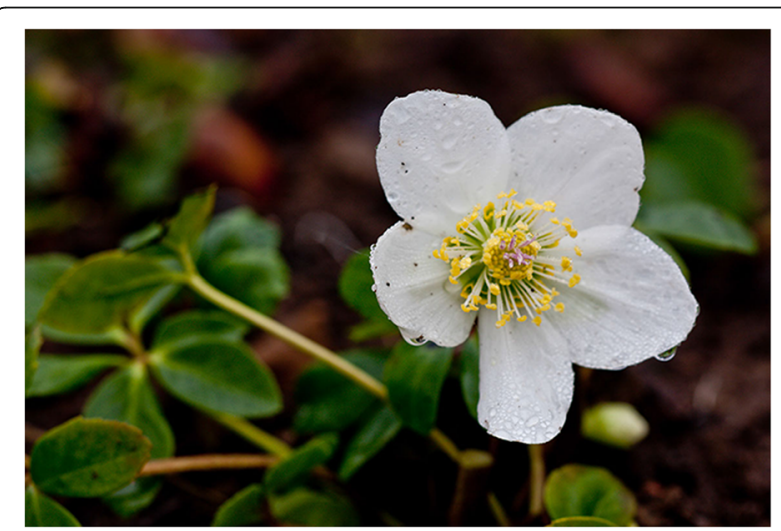

Fig. 1 Helleborus niger L. Black hellebore is a perennial herb with a shallow rhizome blossoming during winter. Taxonomically it is grouped with the Ranunculaceae. Black hellebore has been used as a remedy since ancient times. Because of the multiple components, a broad pharmacological spectrum is ascribed to Christmas rose: anti-bacterial, anti-inflammatory, cholesterol- and blood glucoselowering, neuroprotective, hepatoprotective and immunemodulating effects. With respect to pharmacologically active ingredients, four compound classes are particularly relevant, i.e. steroidal saponins, ranunculin derivatives (including protoanemonin), beta-ecdysone and flavonoids. Photograph was taken by WALA Heilmittel $\mathrm{GmbH}$ related to the renal system because of its diuretic effect and its ability to support elimination of edemas through kidney activation [6].

Black hellebore has only recently regained scientific interest as a plant exhibiting an interesting multi-component profile $[1,2,4-6]$.With respect to pharmacologically relevant ingredients, four compound classes are in the forefront, i.e. the steroidal saponins, the ranunculin derivatives (including protoanemonin), beta-ecdysone and the flavonoids $[4,7,8]$. The latter two exert anabolic and cell protective actions $[9,10]$ while saponins possess the ability to disintegrate membrane structures [11-13]. Protoanemonin is an unsaturated lactone that is formed by deglycosylation from ranunculin, its precursor. Protoanemonin as such is a caustic compound released following comminution of $\mathrm{Hel}$ leborus plant material and - despite its strong tendency to dimerize when occurring as an isolated compound - appears to be fairly stable in aqueous media (unpublished data). Black hellebore, in particular its constituent protoanemonin, has sporadically been suspected to induce genotoxicity, but also anti-mutagenic and even anti-leukemic properties have been reported [14-16]. Though rarely occurring, a large number of the symptoms from poisoning with black hellebore described in the scientific literature can be attributed to the membranolytic properties of some steroidal saponins present in both underground and aerial parts of the plant $[17,18]$. Inter alia, this is expressed by hemolytic activity, hence a potential to disintegrate the cellular membranes of red blood cells [19]. A thorough update of the steroidal saponins with their amphiphilic structures has recently been provided $[4,7,8]$. Among the 38 structures assigned, hellebosaponins A and D were prevailing. This is in contrast to previous reports where macranthosid I was proposed to be the dominating compound [4]. While the roots are especially rich in acetylated polyhydroxy-saponins [8], the aerial parts were characterized by the presence of sarsasapogenyl- and diosgenyl structures [4]. Due to their high solubility in hydrophilic media and their decent stability in isolated conditions, the focus of the present investigation was on the saponins. As in $H N E$, a conversion of the genuine saponin profile proceeds [7], an evaluation of the pharmacological potential of both isolated reference substances and the aqueous fermented extract appeared to be of interest. A causal relationship between compound quantity and pharmacological effect of multi-compound blends cannot be easily drawn. Therefore, by comparison of the complete extract with isolated compounds, the potential of inhibiting cancer cell metabolism and consecutive anti-proliferative effects on living cell systems were investigated. Furthermore the anti-angiogenetic characteristics on HUVEC as well as the anti-proliferative and non-migration properties of $H N E$ on cancer cells were elaborated. The results obtained from these preclinical investigations shall help to better understand the actions of 
black hellebore on healthy and pathological cell systems and shall deepen our understanding into the therapeutic potential of $H$. niger preparations, especially for the treatment of oncologic events.

\section{Methods}

Table 1 shows an overview of the assays used as a basis for the therapeutic potential of HNE. The most important conditions of the assays (cell types, incubation time, reference substances, minimal and maximal concentration of test item) are compiled. The two investigations to evaluate the safety potential of $H N E$ are not included.

\section{Helleborus niger extract (HNE)}

Helleborus niger L. plant material was obtained from our company-owned (WALA Heilmittel $\mathrm{GmbH}$ ) medicinal herb garden, which is located in Bad Boll/Eckwaelden in Southwestern Germany. The cultivation site and identification procedure for plant material used have been described previously [4]: The cultivation areas are maintained following the principles of biodynamic agriculture and organic farming. H. niger L. plants were harvested by botanically well-trained personnel in winter (January). Botanical identification of plant material was carried out by trained staff according to the principles of GACP (good agricultural collection practice), i.e. according to valid requirements for the manufacturing of medicinal products in Europe. Preparation of aqueous-fermented extract of the fresh whole flowering plant was carried out according to the official production protocol described in the German Homeopathic Pharmacopoeia (GHP), aqueous-fermented mother tinctures, protocol number 34c [20]. Two representative batches of $H N E$ (A and B) were used. Batch A contained $4020.5 \mu \mathrm{g} / \mathrm{ml}$ total saponins, 34\% of overall saponin content was hellebosaponin A and $18 \%$ hellebosaponin $\mathrm{D}$, respectively. The content of total saponins in batch B was lower $(2943.0 \mu \mathrm{g} / \mathrm{ml})$, but the percentage of hellebosaponin A was even higher (45\%). Contents of protoanemonin were
$174 \mu \mathrm{g} / \mathrm{ml}$ (batch A) and $90 \mu \mathrm{g} / \mathrm{ml}$ (batch B). All dilutions of $H N E$ were performed with isotonic solution (contains $0.88 \% \mathrm{NaCl}$ and $0.02 \% \mathrm{NaHCO}_{3}$; WALA Heilmittel $\mathrm{GmbH}$ ) except for the reverse mutation assay, where purified water was used (BSL Bioservice, Planegg, Germany).

\section{HPLC-DAD analysis of saponins and protoanemonin}

Quantification of saponin and protoanemonin contents was carried out by high pressure liquid chromatography with diode array detection (HPLC-DAD) using a SunFire ${ }^{\mathrm{mat}}$ C18 $(150 \times 2.1 \mathrm{~mm}$ i.d., $5 \mu \mathrm{m}$ particle size; Waters $\mathrm{GmbH}$, Eschborn, Germany) column for saponin and a Reprosil-AQ reversed phase column $(250 \times 4 \mathrm{~mm}$ i.d., $5 \mu \mathrm{m}$ particle size, Maisch, Ammerbruch, Germany) for protoanemonin analysis, respectively (Fig. 2). $\alpha$-angelica lactone (PhytoLab GmbH \& Co. KG, Vestenbergsgreuth, Germany; purity $79 \%$ ) was used as analytical reference for quantification of protoanemonin and the total saponin content was quantified at $210 \mathrm{~nm}$ using hederacoside C (PhytoLab $\mathrm{GmbH} \&$ Co. KG, Vestenbergsgreuth, Germany; purity $88 \%)$ as a reference. Gradient elution was carried out for both analyte groups, and detection wavelengths were 210 $\mathrm{nm}$ (saponins) and $261 \mathrm{~nm}$ (protoanemonin). Further details on both HPLC methods as well as method validation data have been reported earlier [21].

\section{Isolated steroidal saponins}

Hellebosaponin A, hellebosaponin D and macranthosid I were isolated and purified according to [8]. Chromatographic purity of hellebosaponin A and hellebosaponin D was 97 and $88 \%$ for macranthosid I by high pressure liquid chromatography (HPLC). Isotonic solutions were prepared therefore containing $1.31,0.64$, and $0.12 \mathrm{mg} /$ $\mathrm{ml}$, respectively. Test solutions with isolated steroidal saponins were derived from average contents of 9 different HNE batches. The concentrations employed were representative for their respective content in the $H N E$ batches applied.

Table 1 Overview of the assays used to evaluate the therapeutic potential of HNE

\begin{tabular}{|c|c|c|c|c|c|c|}
\hline Assay & Test principle & Cells & $\begin{array}{l}\text { Incubation } \\
\text { time (h) }\end{array}$ & $\begin{array}{l}\text { Reference } \\
\text { substance }\end{array}$ & $\begin{array}{l}\text { Max. Conc. } \\
(\mu \mathrm{g} / \mathrm{ml})\end{array}$ & $\begin{array}{l}\text { Min. Conc } \\
(\mu \mathrm{g} / \mathrm{ml})\end{array}$ \\
\hline WST-1 & Cell viability & HUVEC & 24 & Paclitaxel & 50,000 & 625 \\
\hline BrdU & Cell proliferation & HUVEC & 24 & Paclitaxel & 50,000 & 625 \\
\hline Matrigel Angiogenese & Tube Formation 2D & HUVEC & 24 & Untreated cells & 829 & 13 \\
\hline $\begin{array}{l}\text { Spheroid-based Cellular } \\
\text { 3D Angiogenesis }\end{array}$ & Tube Formation 3D & HUVEC & 24 & Sunitinib & 20,000 & 20 \\
\hline Alamar Blue & Cell viability $2 \mathrm{D}$ & Tumor cells & 72 & Actinomycin-D & 10,000 & 3.33 \\
\hline Soft Agar & Cell viability 3D & Tumor cells & $216-288$ & Actinomycin-D & 10,000 & 3.33 \\
\hline Oris $^{T M}$ & Cell migration and invasion & Tumor cells & $24-48$ & SKI-606 (Bosutinib) & 1000 & 600 \\
\hline
\end{tabular}

Seven in vitro assays were used to investigate the mechanism of action and the therapeutic potential of HNE for tumor therapy 

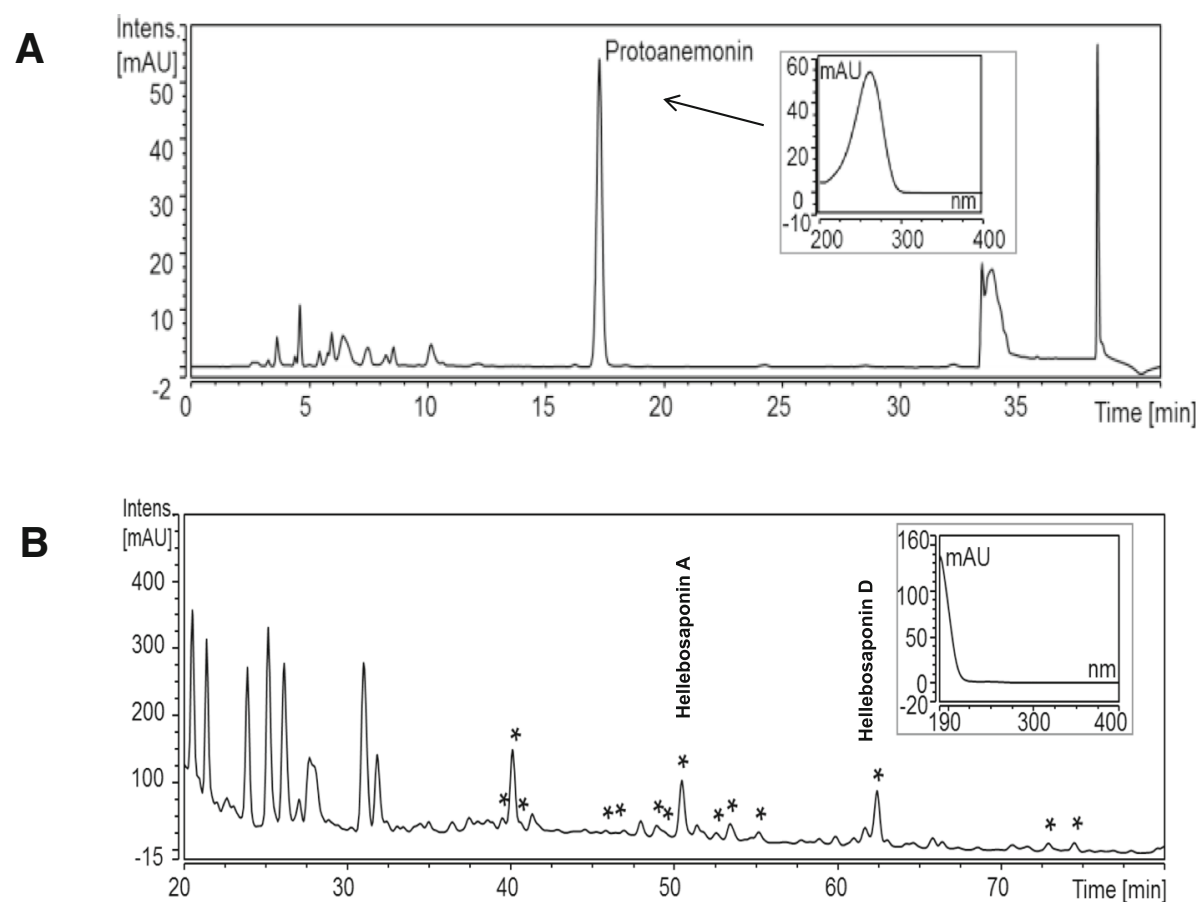

Fig. 2 HPLC-DAD of an aqueous fermented Helleborus niger extract. a: HPLC-DAD chromatogram $(\lambda=261 \mathrm{~nm})$ of an aqueous fermented Helleborus niger extract (1:20 dilution in water) and UVNis spectrum of protoanemonin. $\mathbf{b}$ : HPLC-DAD chromatogram $(\lambda=210 \mathrm{~nm})$ of an aqueous fermented Helleborus niger extract and exemplary UVNis spectrum of a saponin. * Saponins

\section{Reference substances}

Paclitaxel (LC Laboratories, Boston, USA) was used as the reference substance in the Water soluble tetrazolium-assay (WST-1) and Bromodeoxyuridine-assay (BrdU). Its purity was $>99 \%$ by HPLC.

Sunitinib (LC Laboratories, Woburn, USA) was used in the Spheroid-based cellular 3D Angiogenesis assay. Its purity was $>99 \%$ by HPLC.

Actinomycin-D (Sigma-Aldrich Chemie GmbH, Munich, Germany) served as reference substance in the Alamar Blue and Soft Agar assays. Its purity was $\leq 98 \%$ by HPLC.

SKI-606 or Bosutinib (Selleckchem, Munich, Germany) was used in the Oris $^{\text {Tx }}$ Cell Migration and Invasion assay and exhibited a purity of $>99.9 \%$ by HPLC.

\section{HUVEC and cancer cell lines}

In the Alamar Blue and in the Soft Agar assays five cancer cell lines were investigated: Caki-2 (renal cell cancer), MKN-1 (gastric cancer), DLD-1 (colorectal cancer), SK-N-SH (neuroblastoma) and LN 229 (glioblastoma). Additionally, HeLa (cervical carcinoma), HCC827 (lung cancer), A375 and A431 (melanoma), DU-145 (prostate carcinoma), SK-OV3 (ovarian cancer), MDA-MB-231 and MCF-7 (breast cancer) as well as U87-MG (glioblastoma) were tested in the Oris ${ }^{\text {ma }}$ Cell Migration and Invasion assay. All tumor cell lines were provided by ProQinase GmbH (Freiburg, Germany). MKN-1-,
HCC827- and A431-cells were cultivated in RPMI-1640 (Rosewell Park Memorial Institute) containing 10\% FCS (Fetal Calf Serum) and Penicillin / Streptomycin. All remaining cells were kept in DMEM (Dulbecco's Modified Eagle's Medium) containing 10\% FCS and Penicillin / Streptomycin at $37^{\circ} \mathrm{C}$ and $10 \% \mathrm{CO}_{2}$, respectively. A pooled source of Human umbilical vein endothelial cells (HUVEC) was purchased from Promocell (Heidelberg, Germany). These cells are generally used for in vitro angiogenesis assays. HUVEC were cultivated in ECGM (Endothelial Cell Growth Medium) and ECBM (Endothelial Cell Basal Medium) with $20 \% \mathrm{FCS}$ for $24 \mathrm{~h}$ at $37^{\circ} \mathrm{C}, 5 \% \mathrm{CO}_{2}$ and $95 \%$ humidity prior to addition of individual test items.

\section{Safety assessment}

Two preclinical investigations to improve the safety profile of $H$. niger were carried out in compliance with good laboratory practice.

\section{Reverse mutation assay (Ames test)}

Tests with $H N E$ were performed by BSL Bioservice Scientific Laboratories GmbH (Planegg, Germany) according to Organisation for Economic Cooperation and Development (OECD) guidelines [22]. Specified tester strains of Salmonella typhimurium TA98, TA100, TA1535, TA1537, and TA102 were used in the plate-incorporation and the pre-incubation method, 
respectively. Both tests were performed with and without metabolic activation using mammalian microsomal fraction Supernatant $9000 \times$ g (S9) mix preparation according to Ames et al. [23] or S9 mix substitution phosphate buffer $(0.2 \mathrm{M})$, respectively. For each experiment, $100 \mu \mathrm{l}$ of several dosing levels of $H N E$ diluted in purified water up to the maximum concentration according to recommendations from the OECD guideline [22] and concentration finding experiments in a pre-experiment for toxicity evaluation were applied $(0.0316,0.100,0.316$, 1.0, 2.5 and $5.0 \mu \mathrm{l} /$ plate). Purified water was used as negative control and strain-specific positive controls were applied in parallel [20]. Samples including negative and positive controls were tested in triplicate. Results were evaluated for cytotoxic and mutagenic effects using criteria described by OECD [22].

\section{Hemolytic potential}

The hemolytic activity on human erythrocytes was investigated by Harlan CCR (Rossdorf, Germany) according to the design of the International Organization for Standardization (ISO) 10993 guideline. Undiluted HNE, dilutions thereof at concentrations ranging from 100 to $0.001 \mu \mathrm{l} / \mathrm{ml}$ (in intervals of 1:10), each in isotonic solution, were treated with erythrocyte suspension while being shaken for $3 \mathrm{~h}$ at room temperature in the dark. Concentrations were chosen taking into account the concentrations used in medical treatment. Erythrocytes were obtained from donor blood free from medication. The diluted blood was centrifuged for $5 \mathrm{~min}$ at 2000 rpm, the supernatant discarded and the erythrocyte pellet washed three times with physiological sodium chlorine solution. Subsequently, the washed cells were re-suspended in saline such that $25 \mu$ of the suspension in $1 \mathrm{ml}$ of de-ionized water resulted in an absorbance of 2.1 at $575 \mathrm{~nm}$. Saline and de-ionized water, serving as negative and positive controls respectively, were equally treated. After centrifugation at about $3000 \mathrm{xg}$ for $1 \mathrm{~min}$, absorbance of the supernatants derived from treated erythrocytes was measured at a wavelength of $530 \mathrm{~nm}$. Absorbance values analyzed subsequent to erythrocyte treatment were corrected with absorbance values from untreated test items. Hemolysis was reported as the percentage of the hemoglobin liberated from the erythrocytes, measured as mean absorbance values corrected by absorbance values of untreated test items, as compared to positive control (100\% lysis).

\section{Anti-angiogenesis and tube formation}

Angiogenesis, the formation of new blood vessels from pre-existing ones, is a balanced physiological process during growth and development. Among others, angiogenesis is also mandatory for invasive tumor progression. Therefore, the anti-angiogenetic impact of $H N E$ was tested.

\section{WST-1}

Prior to performing the Matrigel Angiogenesis assays, the cytotoxic activity of $H N E$ on HUVEC was investigated by a colorimetric assay. Cell viability was quantified by transformation of the tetrazolium salt WST-1. Cells in supplemented cell culture medium were plated $\left(2.5 \times 10^{3}\right.$ per well $)$ in a volume of $100 \mu \mathrm{l}$ and incubated for $24 \mathrm{~h}$ at $37^{\circ} \mathrm{C}, 5 \% \mathrm{CO}_{2}$ and $95 \%$ humidity prior to the addition of test items. Cells cultured with medium alone served as negative control. Paclitaxel in DMSO was tested as reference item in final concentrations of 8539.06-0.0085 $\mu \mathrm{g} / \mathrm{ml}$. The following dilutions of $H N E$ were used: 1:20, 1:100, 1:500, 1:2500, 1:12,500, 1:62,500 and 1:312,500 according to previous investigations [2, 5, 6]. Each test item in each dilution was analyzed in triplicate. Cells were incubated in the presence of test items for $24 \mathrm{~h}$. WST-1 (cell proliferation reagent WST-1, supplied as ready-to-use solution, Roche Molecular Biochemicals, Mannheim, Germany) was added ( $20 \mu \mathrm{l}$ per well), incubated at $37^{\circ} \mathrm{C}$ and the optical density (OD) was determined after $4 \mathrm{~h}$. OD was measured in an ELISA reader (FluoStar Optima, BMG Lab-tech, Germany) at wavelength settings of $450 \mathrm{~nm}$ and $645 \mathrm{~nm} . \mathrm{OD}_{645 \mathrm{~nm}}$ was subtracted from the $\mathrm{OD}_{450 \mathrm{~nm}}$ to correct for background.

\section{BrdU}

The second step was to evaluate the anti-proliferative efficacy of HNE in dilutions similar to WST-1 and to define the concentration of $H N E$ to be used in the Matrigel Angiogenesis assay.

A chemiluminescent cell proliferation assay (Roche Diagnostics Deutschland GmbH, Mannheim, Germany) was performed according to the manufacturer's instructions. HNE was diluted in 1:20, 1:100, 1:500, 1:2500, 1:12,500, 1:62,500 and 1:312,500 according to previous investigations $[2,5,6]$. Paclitaxel was tested as positive reference in concentrations of $8539.06-0.0085 \mu \mathrm{g} / \mathrm{ml}$. In addition, cells cultured with medium alone served as negative control. Cells were incubated for $24 \mathrm{~h}$. Luminescence was measured in an enzyme-linked immunosorbent assay (ELISA) reader FluoStar Optima (BMG Labtech, Ortenberg, Germany). Each test item in each dilution was tested in triplicate.

\section{Matrigel angiogenesis assay}

This test monitors the ability of HUVEC to form capillary-like structures (tubes) in $2 \mathrm{D}$ in the presence of added dilutions at non-cytotoxic levels assessed in the WST-1. This in vitro method was performed as described by Ponce [24] with minor modifications by 
HeidelbergPharma GmbH (Heidelberg, Germany). HUVEC with ECGM, supplement mix (Promocell, Heidelberg, Germany) and 20\% heat inactivated FCS in the matrigel-well were incubated in duplicate with $H N E$ dilutions that had been previously determined in BrdU as inhibitory concentration of $10 \%\left(\mathrm{IC}_{10}\right)$ (batch A: $13 \mu \mathrm{g} / \mathrm{ml}$; batch B: $35 \mu \mathrm{g} / \mathrm{ml})$, inhibitory concentration of $50 \%\left(\mathrm{IC}_{50}\right)$ (batch A: $69 \mu \mathrm{g} / \mathrm{ml}$; batch B: $170 \mu \mathrm{g} / \mathrm{ml}$ ) and inhibitory concentration of $90 \%\left(\mathrm{IC}_{90}\right)$ (batch $\mathrm{A}: 354 \mu \mathrm{g} / \mathrm{ml}$; batch B: $829 \mu \mathrm{g} / \mathrm{ml})$. After $24 \mathrm{~h}$, cells were labeled with $8 \mu \mathrm{g} / \mathrm{ml} \mathrm{Cal}-$ cein AM Fluorescent Dye (Bectin Dickinson, Heidelberg, Germany) and examined under a microscope. A digital photograph was taken and the cell-covered area (in $\mu \mathrm{m}^{2}$ ) in each representative area (ROI) was determined.

\section{Spheroid-based cellular 3D angiogenesis assay}

Verifying the results of the in vitro Matrigel Angiogenesis assay, a second angiogenesis assay in 3D dimension was performed by ProQinase $\mathrm{GmbH}$ (Freiburg, Germany). Experiments were conducted in modification of the originally published protocol by Korff and Augustin [25]. $H N E$ was tested for its ability to inhibit vascular endothelial growth factor A (VEGF-A) induced endothelial cell (EC) sprouting. Spheroids are prepared by pipetting 500 HUVEC in a hanging drop on plastic dishes to allow overnight spheroid aggregation [26]. Fifty spheroids were seeded in a collagen solution to allow collagen gel polymerization. Test items (HNE diluted in 1:50, 1:167, $1: 500,1: 1667,1: 5000,1: 16,667$ and 1:50,000 based on results from concentrations used in the 2D Angiogenese assay), Sunitinib (3984.8-3.99 $\mu \mathrm{g} / \mathrm{ml})$ and hVEGF-A 165 (ProQinase $\mathrm{GmbH}$, Freiburg, Germany) with a final assay concentration of $25 \mathrm{ng} / \mathrm{ml}$ were added on top of the polymerized gel. Following incubation for $24 \mathrm{~h}$, plates were fixed by adding 4\% Roti-Histofix (Roth, Karlsruhe, Germany). Sprouting intensity of EC spheroids is quantified by determining the cumulative sprout length per spheroid using an inverted microscope and digital imaging software analysis (Soft imaging system, Muenster, Germany). The mean of the cumulative sprout length of 10 randomly selected spheroids is considered as an individual data point. The median of basal sprouting was subtracted from all other median data points.

\section{In vitro assessment of anti-cancer potential}

The following three in vitro assays, performed by ProQinase $\mathrm{GmbH}$ (Freiburg, Germany), were applied to assess the impact of $H N E$ on different human cancer cell lines.

\section{Proliferation-assays: Alamar blue and soft agar assays}

Both the 2D Alamar Blue and the 3D Soft Agar assay are based on the quantification of the population of living cells after compound incubation using a fluorescent cell viability dye. The test items were $H N E$ at a dilution of 1:100 with further semi-logarithmic dilution steps according to the standard concentration range in these assays: isotonic solution, Actinomycin-D ( $<98 \%$ purity) and Staurosporine (Sigma-Aldrich Chemie $\mathrm{GmbH}$, Munich, Germany) (purity $>95 \%$ by HPLC). In the 2D Alamar Blue assay the following isolated compounds from $H$. niger were investigated: $0.12 \mathrm{mg} / \mathrm{ml}$ macranthosid I, $1.31 \mathrm{mg} / \mathrm{ml}$ hellebosaponin $\mathrm{A}, 0.64 \mathrm{mg} / \mathrm{ml}$ hellebosaponin D as well as the combination of these three steroidal saponins. The incubation time was $72 \mathrm{~h}$ in the 2D Alamar Blue assay and 9 days for DLD-1, SK-N-SH, MKN-1 and LN229 as well as 12 days for Caki-2 in the 3D Soft Agar assay. Each sample was submitted to three independent experiments.

\section{Migration assay}

Cancer cells are able to migrate, intrude into other tissues and form metastases. HNE was tested for its impact on migration of human tumor cell lines. For this purpose, the Oris ${ }^{\text {rat }}$ Cell Migration and Invasion assay was used. Cells were seeded $(40,000$ cells in $100 \mu \mathrm{l}$ of medium/well) onto Collagen-I-coated 96-well plates (ORIS $^{\text {mi }}$, AMS Bio, Cambridge, UK). Vials were equipped with stoppers to restrict cell seeding to the outer annular regions of the well. Removal of the stopper $18 \mathrm{~h}$ after seeding reveals an unseeded region in the center of each well, i.e. the detection zone, into which the seeded cells then may migrate during $24-48 \mathrm{~h}$ in the absence or presence of inhibitors. HNE was added after removing the stopper at concentration levels chosen by means of the results from all previous tests: $600 \mu \mathrm{g} / \mathrm{ml}$ for batch A and $1000 \mu \mathrm{g} / \mathrm{ml}$ for batch B. This is roughly equivalent to the homeopathic potency D3. All concentration levels of $H N E$ were monitored in triplicate. Zero control (with stopper inserts) was carried out 4-fold and positive control (solvent) 5-fold. SKI-606 was used as reference compound and assessed at six different concentration levels in singlicate $(5304.46-0.053 \mu \mathrm{g} / \mathrm{ml})$. Fluorescence data was determined using fluorescence plate reader. The mean value of solvent controls was set to $100 \%$ and the mean value of zero control was set to $0 \%$.

\section{Statistical analysis}

All standard deviations (SD) are shown in the Additional file 1.

GraFit Version 5.0.13 from Erithacus Software Ltd. (West Sussex, U. K.) was used for calculating of $\mathrm{IC}_{50}$ in WST-1 and BrdU.

In the Matrigel Angiogenesis assay the cell-covered area in untreated control wells (mean of 6 ROI in 2 wells) and test item-treated wells (mean of 6 ROI in 2 wells) were compared.

Raw data were converted into percent EC sprouting relative to high control (VEGF-A sprouting) which was 
set to $100 \%$ for the spheroid-based Cellular 3D Angiogenesis assay and into percent cell viability relative to high (solvent) and low (Staurosporine), which were set to 100 and $0 \%$ for the proliferation assays, respectively. For these methods GraphPadPrism Version 5 from GraphPad Software (La Jolla, USA) was used for calculating $\mathrm{IC}_{50}$. For each compound, the level of migration was calculated in $\%$ migration of solvent control.

\section{Results}

\section{Safety evaluation}

\section{Reverse mutation assay}

As part of the safety assessment of $H N E$, a bacterial reverse mutation assay was performed. In both independent experiments, no biologically relevant increase in revertant colony numbers of any of the five tester strains were observed following treatment with $H N E$ at any test concentration up to the maximum exposure level recommended by OECD [22]. Metabolic activation by addition of mammalian liver microsomes did not reveal any potential to induce gene mutations. Reference mutagens induced a distinct increase of revertant colonies indicating the validity of the experiments. No biologically relevant increases in revertant colony numbers of any of the five tester strains were observed following treatment with $H N E$ at any concentration level required by OECD [22]. The reference mutagens induced distinct increases of revertants (Fig. 3, see Additional file 1, 1st tab). Therefore, $H N E$ is considered as non-mutagenic in this bacterial reverse mutation assay.

\section{Hemolytic potential}

The hemolytic activity of the $H N E$ was investigated in vitro in human erythrocytes. With a hemolysis value of $62.70 \%$, the $100 \mu \mathrm{l} / \mathrm{ml}$ dilution of the extract was classified as hemolytic. This value was above the threshold for hemolysis defined as $>5 \%$ in comparison with de-ionized water as positive control. In contrast, hemolysis was not observed for $H N E$ at all lower concentration levels analyzed from $10 \mu \mathrm{l} / \mathrm{ml}$ downwards, leading to values of 2.48 , $1.90,1.68,1.79,2.90$, and $2.21 \%$, respectively. Standard deviations in this assay were between 0 and 0.0145 (see Additional file $1,2 \mathrm{nd}$ tab). It can therefore be concluded that in the hemolysis test performed, $H N E$ at concentrations up to $10 \mu \mathrm{l} / \mathrm{ml}(1: 100(\mathrm{v} / \mathrm{v})$ dilution of $H N E)$ did not induce any hemolytic effects.

\section{Anti-angiogenesis and tube formation Matrigel angiogenesis assay}

The concentration of $H N E$ was predetermined with the BrdU design: $H N E$ showed an anti-proliferative potency on HUVEC. The mean value of $\mathrm{IC}_{50}$ concentration of batches $\mathrm{A}$ and $\mathrm{B}$ of $H N E$ was $120 \pm 50.5 \mu \mathrm{g} / \mathrm{ml}$. The reference item (Paclitaxel) is highly potent in the inhibition

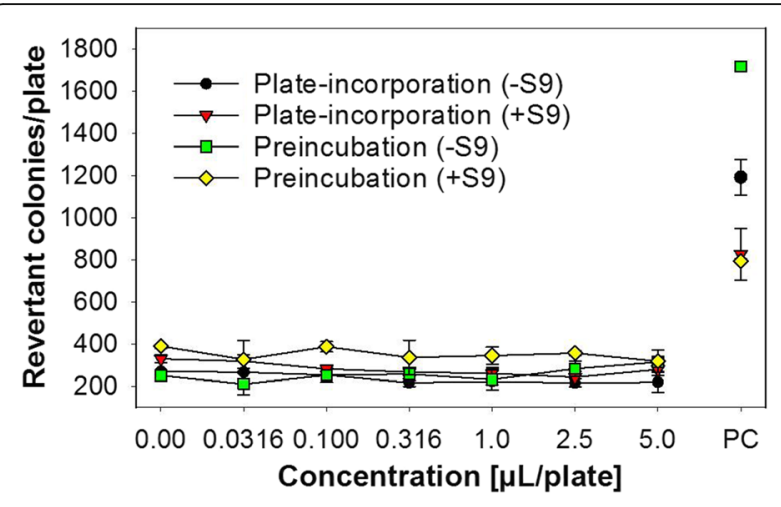

Fig. 3 Results from Ames tests on HNE. Data from tester strain S. typhimurium TA102 are exemplarily presented. PC = positive controls

of cell proliferation $\left(\mathrm{IC}_{50}=0.57 \mu \mathrm{g} / \mathrm{ml}\right)$. This chemotherapeutic agent belongs to the taxane group and inhibits the degradation of the microtubules and disrupts cell division.

Prior to the BrdU assay, the cytotoxic potential of HNE on HUVEC was evaluated by WST-1. The mean value of $\mathrm{IC}_{50}$ concentration of the two $H N E$ batches was $288 \pm 3.5 \mu \mathrm{g} / \mathrm{ml}$. The reference item (Paclitaxel) was less potent in the inhibition of cellular metabolism $\left(\mathrm{IC}_{50}=\right.$ $1238 \mu \mathrm{g} / \mathrm{ml}$ ).

The two HNE batches reduced the HUVEC tube formation in the Matrigel Angiogenesis assay in a concentrationdependent manner by up to $50.1 \pm 9.2 \%$ and $49.4 \pm 5.3 \%$ at concentrations of $354 \mu \mathrm{g} / \mathrm{ml}$ and $829 \mu \mathrm{g} / \mathrm{ml}$, respectively.

\section{Spheroid-based cellular 3D angiogenesis assay}

In the second tube formation assay, HNE was tested for its ability to inhibit VEGF-A induced cellular EC sprouting. The mean value of $\mathrm{IC}_{50}$ concentration of the two $H N E$ batches was $172 \pm 11.5 \mu \mathrm{g} / \mathrm{ml}$. In comparison, the reference substance Sunitinib with an $\mathrm{IC}_{50}$ value of $11.95 \mu \mathrm{g} / \mathrm{ml}$ exhibited a stronger inhibitory effect.

\section{In vitro assessment of anti-cancer potential Proliferation assays: Alamar blue assay and soft agar assay} The mean $\mathrm{IC}_{50}$-values amounted to $202-549 \mu \mathrm{g} / \mathrm{ml}$ in the Alamar Blue and to $176-584 \mu \mathrm{g} / \mathrm{ml}$ in the Soft Agar assays for the six tumor cell lines chosen (Table 2, Fig. 4). The gastric cancer cell line MKN-1 responded most sensitively and the $\mathrm{IC}_{50}$ of brain tumor cell lines was approximately twofold higher than on other cells. The reference compound Actinomycin-D showed an $\mathrm{IC}_{50}$ of $5.40 \mu \mathrm{g} / \mathrm{ml}$ on Caki-2 and between $1.63 \mu \mathrm{g} / \mathrm{ml}$ and $1.02 \mu \mathrm{g} / \mathrm{ml}$ on the other cell lines in the $2 \mathrm{D}$ design (Table 2). In the 3D model, $\mathrm{IC}_{50}$ values on Caki-2 were 8.79 for Actinomycin-D and between 0.31 and $1.00 \mu \mathrm{g} / \mathrm{ml}$ on the other cell lines (Table 2).

In addition to the investigations on whole $H N E$, isolated components from $H N E$ were also tested in the 
Table $2 \mathrm{IC}_{50}$ concentrations $(\mu \mathrm{g} / \mathrm{ml})$ of HNE in the 2D Alamar Blue assay and 3D Soft Agar assay

\begin{tabular}{|c|c|c|c|c|c|c|c|c|c|c|}
\hline \multirow[b]{2}{*}{ Cell type } & \multicolumn{5}{|c|}{ 2D Alamar Blue assay } & \multicolumn{5}{|c|}{ 3D Soft Agar assay } \\
\hline & Batch A HNE & Batch B HNE & Mean HNE & SD & Actinomycin-D & Batch A HNE & Batch B HNE & Mean HNE & SD & Actinomycin-D \\
\hline Caki-2 & 220 & 430 & 291 & 105 & 5.40 & 140 & 430 & 211 & 145 & 8.79 \\
\hline DLD-1 & 210 & 330 & 257 & 61.5 & 1.58 & 170 & 340 & 227 & 35 & 0.99 \\
\hline MKN-1 & 170 & 250 & 202 & 90 & 1.02 & 130 & 270 & 176 & 70 & 0.82 \\
\hline LN229 & 460 & 680 & 549 & 110 & 1.51 & 440 & 870 & 584 & 215 & 0.31 \\
\hline SK-N-SH & 260 & 490 & 340 & 115 & 1.63 & 330 & 490 & 394 & 80 & 1.00 \\
\hline
\end{tabular}

Two HNE batches (A, B) were analyzed in comparison to Actinomycin-D in five tumor cell lines (Caki-2: renal cell carcinoma, DLD-1: colorectal carcinoma, MKN-1: gastric carcinoma, LN 229: glioblastoma, SK-N-SH: neuroblastoma) for their anti-proliferative potential in the 2D designed Alamar Blue assay and in the 3D designed Soft Agar assay. (Standard deviations of the results (growth levels relative to high control (isotonic solvent (100\%)) are presented in Additional file 1)

Alamar Blue assay. Hellebosaponin D $(0.64 \mathrm{mg} / \mathrm{ml})$ and macranthosid I $(0.12 \mathrm{mg} / \mathrm{ml})$ did not have any effect on the proliferation of the tested tumor cell lines. Hellebosaponin A $(1.31 \mathrm{mg} / \mathrm{ml})$ showed less activity than $H N E$ on DLD1, SK-N-SH and MKN-1 cells $\left(\mathrm{IC}_{50} \mathrm{DF}=\varnothing\right.$ 1:332); the combined preparation of the three separate components had an even lower effect $\left(\mathrm{IC}_{50} \mathrm{DF}=\varnothing\right.$ 1:151). Hellebosaponin A and the combined preparation of the isolated saponins showed no activity on Caki-2 and LN229 cells (Table 3, Fig. 4).

\section{Oris $^{\mathrm{TM}}$ cell migration and invasion assay}

The ability to inhibit the tumor cell migration was investigated on a panel of 14 cell lines. In the concentration range of $600-1000 \mu \mathrm{g} / \mathrm{ml}$, migration was inhibited by more than $80 \%$ on the neuroblastoma cell line SK-N-SH, the renal cell cancer cell line Caki-2 and the colorectal cancer cell line DLD-1. Moreover, the migration was inhibited by $60-80 \%$ on the glioblastoma cell line LN229, the cervical cancer cell line HeLa and the lung cancer cell line HCC 827. Inhibition $<60 \%$ was found in melanoma-, prostate carcinoma-, ovarian cancer- and breast cancer cell lines. $H N E$ had a very strong (>100\%) inhibition on MKN-1 cells. The reference substance SKI-606 had a lower effect on MKN-1, SK-N-SH and Caki-2 than HNE and a comparable impact on DLD-1, LN229 and HeLa (Fig. 5). Standard deviations in this assay were between 0 and 23 (Fig. 5, see Additional file 1, 9th tab).

\section{Discussion}

Although $H$. niger L. has been used as a herbal remedy for a long time, literature data still leave some uncertainties for a thorough risk assessment of the plant and extracts from it. The lactone proteoanemonin and the steroidal saponins are reported as main toxic compounds from black hellebore $[1,2]$. Hence, the first part of the current research aimed to fill this gap by providing data on the preclinical safety of $H N E$ used in the manufacture of medicinal products.

Genotoxicity testing is a main element in profiling the safety of herbal preparations for medical use. The Ames test is the method of choice because of its suitability to assess initial mutagenicity. The test has been shown to detect relevant genetic changes [22,27] with a specificity of $74 \%$ compared to less than $45 \%$ in mammalian cell tests [28]. In the present study, an Ames test performed with $H N E$ did not reveal any mutagenic effects neither with nor without metabolic activation by mammalian enzymes. Up to the maximum exposure level recommended by OECD [22], HNE did not cause gene mutations by base pair changes or frameshifts in the genome of the tester strains used in two independent experiments. Therefore, $H N E$ is considered as non-mutagenic in this bacterial reverse mutation assay. Consequently, in accordance with the Committee on Herbal Medicinal Products of the European Medicines Agency (EMA's HMPC) [27], the safety of the herbal preparation for use in traditional herbal medicine is sufficiently proven. Furthermore, results are in line with a recent publication by Schrenk et al. [29]. Therein, authors stated that neither structure-activity-relationship assessments, computer-assisted toxicity evaluation, nor comprehensive literature research revealed any evidence for a genotoxic, carcinogenic, or teratogenic potential of protoanemonin.

In the current study, the hemolytic potential of $H N E$ containing steroidal saponins was investigated in vitro in human erythrocytes at different concentration levels. Hemolysis values above the threshold defined as $>5 \%$ positive control were revealed for the $100 \mu \mathrm{l} / \mathrm{ml}$ dilution of HNE in isotonic solution and classified as hemolytic. In contrast, hemolysis was not observed for $H N E$ at concentration levels up to $10 \mu \mathrm{l} / \mathrm{ml}$. It can be concluded that in the hemolysis test performed, $H N E$ at concentrations up to $10 \mu \mathrm{l} / \mathrm{ml}$ did not induce any hemolytic effects. The level at which no hemolytic effect was observed is above the maximum bioavailable concentration expected from application of $H N E$ products in humans by several orders of magnitude. Therefore, the use of $H N E$ in herbal medicinal products can be considered as safe.

The aim of the second part of this investigation was to obtain a better understanding of the therapeutic potential of $H N E$ in vitro used as a medicinal product in 


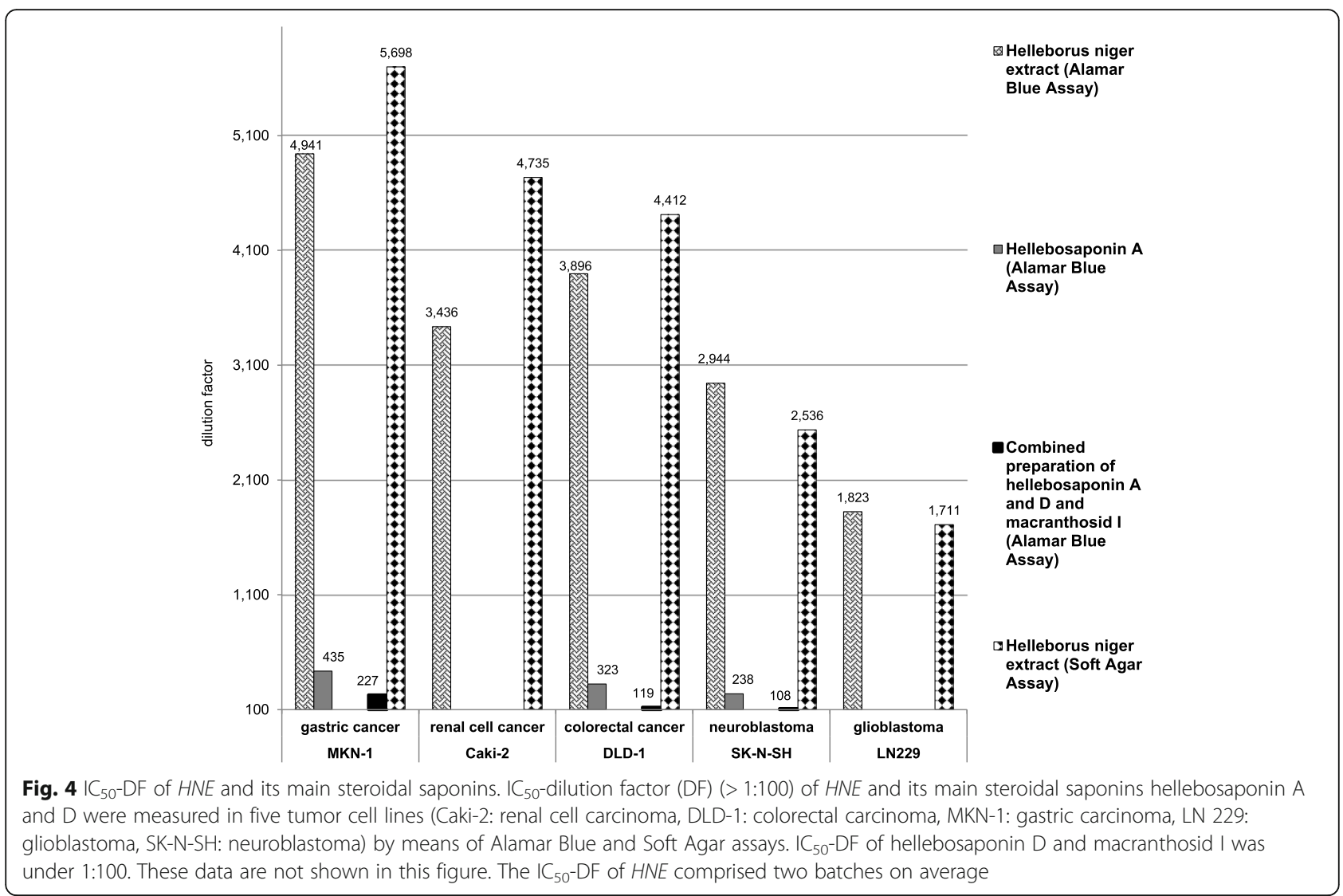

oncology. First the impact on the angiogenesis process was evaluated. Angiogenesis is mandatory for tumor progression [30, 31]. The Matrigel Angiogenesis assay monitors the ability of HUVEC to form capillary-like structures (tubes) as a prerequisite for invasive cell growth. HNE batches reduced the HUVEC tube formation in a concentration-dependent manner by up to 50.1 and $49.4 \%$ at concentrations of 354 and $829 \mu \mathrm{g} / \mathrm{ml}$, respectively. The width of the concentration range is very large. We assume that there is an effect of saturation for $H N E$ on the concentration level because the tube formation could not be stopped. In addition, on the time level the tube formation continues as the $H N E$ uptake rate of the tissue is higher than the application of $H N E$. The second tube formation assay showed that $172 \mu \mathrm{g} / \mathrm{ml}$ $H N E$ inhibited $50 \%$ of VEGF-A induced EC sprouting. This result correlates with the strong proliferation inhibition found for HUVEC in BrdU. As the VEGF-A is operating in $3 \mathrm{D}$, it is more sensitive than the Matrigel Angiogenesis. The reference substance Sunitinib had a stronger inhibitory effect than $H N E$ because Sunitinib inhibits all receptors for platelet-derived growth factor and vascular endothelial growth factor receptors, which play a role in tumor angiogenesis and tumor cell proliferation.

Subsequently, the anti-proliferative impact was evaluated in different tumor cell lines using cellular proliferation assays accepted in oncology for analyzing the

Table $3 \mathrm{IC} 50$ DF of the characteristic compounds at concentrations levels present in HNE

\begin{tabular}{lllll}
\hline Cell type & Macranthosid I $(0.12 \mathrm{mg} / \mathrm{ml})$ & Hellebosaponin A $(1.31 \mathrm{mg} / \mathrm{ml})$ & Hellebosaponin D $(0.64 \mathrm{mg} / \mathrm{ml})$ & Combined preparation \\
\hline Caki-2 & $<1: 100$ & $<1: 100$ & $<1: 100$ & $<1: 100$ \\
DLD-1 & $<1: 100$ & $1: 323$ & $<1: 100$ & $1: 119$ \\
MKN-1 & $<1: 100$ & $1: 435$ & $<1: 100$ & $1: 227$ \\
LN229 & $<1: 100$ & $<1: 100$ & $<1: 100$ & $<1: 100$ \\
SK-N-SH & $<1: 100$ & $1: 238$ & $<1: 100$ & $1: 108$
\end{tabular}

Macranthosid I, hellebosaponin A and D are the characteristic compounds in HNE. These three compounds were isolated and investigated at concentration levels presented in HNE for their anti-proliferative potential by means of Alamar Blue assay. $\mathrm{IC}_{50}$ dilution factor (DF) of the combined preparation of all three compounds was examined in five tumor cell lines (Caki-2: renal cell carcinoma, DLD-1: colorectal carcinoma, MKN-1: gastric carcinoma, LN 229: glioblastoma, SK-N-SH: neuroblastoma) as well 


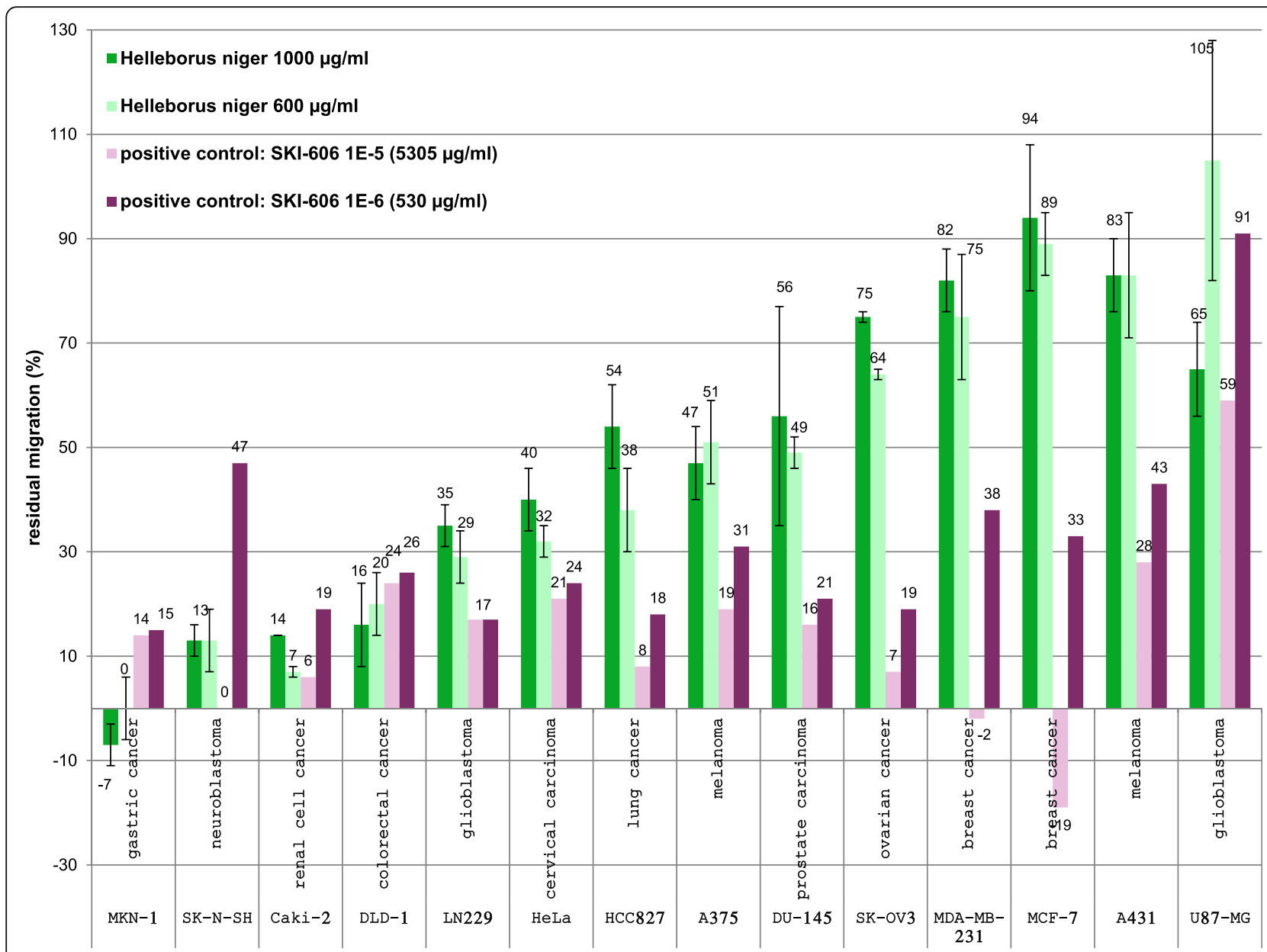

Fig. 5 Residual migration (\%) of cancer cells after treatment with HNE. Residual migration (\%) of 14 cancer cell lines after treatment with HNE in two different concentrations ( 600 and $1000 \mu \mathrm{g} / \mathrm{ml}$ ) compared to positive control SKI-606 in two concentrations $(530 \mu \mathrm{g} / \mathrm{ml}, 5305 \mu \mathrm{g} / \mathrm{ml}$ ) after $24-$ $48 \mathrm{~h}$ depending on tumor cell lines. The cell line panel included gastric cancer (MKN-1), neuroblastoma (SK-N-SH), renal cell cancer, colorectal cancer (DLD-1), glioblastoma (LN 229 and U87-MG), cervical carcinoma (HeLa), lung cancer (HCC827), melanoma (A375 and A431), prostate carcinoma (DU-145), ovarian cancer (SK-OV3) and breast cancer (MDA-MB-231 and MCF-7). Value ranges over 100\% do not mean a support of tumor cell migration but are rather due to artifact interactions in the assay

impact of anti-cancer drugs. The most common cellular phenotypic assay is the $2 \mathrm{D}$ proliferation assay, which is generally regarded as a pretest to more sophisticated assays such as apoptosis or the 3D Soft Agar assay. Anchorage-independent cell growth measured in the 3D Soft Agar assay is one of the hallmark characteristics of cellular transformation and uncontrolled cell growth, with normal cells typically not capable of proliferating in semisolid matrices. 3D cell growth is more similar to the in vivo cellular environment. In the current investigations, HNE showed a dose-dependent anti-proliferative activity both in two- and three-dimensional extension on all five cell lines. The results of the $2 \mathrm{D}$ model were related to the assay in $3 \mathrm{D}$ design and were comparable to those from the WST-1 (Ø IC $\left.\mathrm{I0}_{50}=288 \mu \mathrm{g} / \mathrm{ml}\right)$.

The gastric cancer cell line MKN-1 and the colorectal cell line DLD-1 as well the renal cell cancer cell line
Caki-2 responded most sensitively. The $\mathrm{IC}_{50}$ of brain tumor cell lines was approximately twofold higher than these cells, i.e. they are less sensitive towards $H N E$ treatment. The reference compound Actinomycin-D, a cytotoxic antibiotic, showed a high anti-proliferative effect. It binds to Deoxyribonucleic acid (DNA) and can inhibit Ribonucleic acid- (RNA) synthesis. These results prefigure on a therapeutic potential of HNE not only on brain tumor or renal cell tumors, but also on gastric and colorectal cancer. This effect was confirmed in the third set of assays performed with tumor cell lines: The migration of tumor cells is considered to be an important factor for tumor spreading. Cancer cells are able to migrate, intrude into other tissues and form metastases. Therefore the Oris ${ }^{\mathrm{Tx}}$ Cell Migration and Invasion assay with 14 different human tumor cell lines was performed. This assay represents an alternative to the Scratch assay because 
the cell seeding stoppers create a consistent detection zone to monitor $2 \mathrm{D}$ closure. In the concentration range of $600-1000 \mu \mathrm{g} / \mathrm{ml}$, migration was inhibited by more than $80 \%$ on the colorectal cancer cell line DLD- 1 . The very strong inhibition (>100\%) on MKN-1 cells can be attributed to a cytotoxic effect (Alamar Blue assay: $\mathrm{IC}_{50}$ $=130 \mu \mathrm{g} / \mathrm{ml}$ ). The inhibition of cell migration after treatment with $H N E$ was very strong (>90\%) on SK-N-SH and strong $(\sim 70 \%)$ on LN229, but there was only a little effect on U87-MG glioblastoma cells, grade IV, which are refractory to chemotherapy in most cases. Value ranges over $100 \%$ do not mean a support of tumor cell migration but are rather due to artifact interactions in the assay. A very strong inhibition (90\%) was also determined on the renal cancer cell line Caki-2, which is a valid proof for the current main therapeutic use [29]. Moreover, the migration was inhibited by $60-80 \%$ on the cervical cancer cell line HeLa and the lung cancer cell line HCC827, respectively. Inhibition $<60 \%$ was found in melanoma-, prostate carcinoma-, ovarian cancer- and breast cancer cell lines as well as for the reference substance SKI-606 at a concentration of $530 \mu \mathrm{g} / \mathrm{ml}$ on U87-MG, A431 and SK-N-SH. SKI-606 is an ATP-competitive Bcr-Abl tyrosine-kinase inhibitor with an additional inhibitory effect on SRc family kinases currently undergoing research for use in cancer treatment.

In addition to the investigations of whole $H N E$, isolated components from $H N E$ were also tested in the Alamar Blue assay and showed less or no activity. The concentrations employed were representative for their content in the $H N E$ batches applied. Hellebosaponin D and macranthosid I did not exert any effect on the cell proliferation. Hellebosaponin A showed about 10-fold lower activity than HNE on DLD1, SK-N-SH and MKN-1 cells. The combined preparation of the three separate components exhibited an even lower effect. This prefigures that other ingredients of the whole aqueous fermented extract and not primarily steroidal saponins are responsible for the anti-proliferative effects detected.

\section{Conclusion}

$H N E$ has neither genotoxic nor hemolytic potential. The current investigations verify the anti-proliferative, antiangiogenetic and migration-inhibiting effect of $H N E$, broader than only on brain and renal cell tumors thus far associated with $H N E$ treatment. The gastric cancer cell line MKN-1 responded with the greatest sensitivity, but even in DLD-1 cells (colorectal cancer) a significant anti-tumor effect was detectable, suggesting an extended field of therapeutic potential. The lower impact of the isolated characteristic steroidal saponins from $H N E$ tested separately indicates that the therapeutic effect cannot be reduced to the steroidal saponins, but rather the complete aqueous fermented extract is the active principle. Concomitantly, a good safety profile was corroborated.

\section{Additional file}

Additional file 1: Shows the results with their standard deviations (SD) in detail for all methods separated by individual tabs. 1st tab: Genotox (Ames-test). 2nd tab: Hemolysis-test. 3rd tab: WST-1. 4th tab: BrdU. 5th tab: 2D angiogenesis assay (Matrigel Angiogenesis). 6th tab: 3D angiogenesis assay (Spheroid-based Cellular 3D). 7th tab: 2D proliferation assay (Alamar Blue). 8th tab: 3D proliferation assay (Soft Agar). 9th tab: Migration assay (ORIS ${ }^{\text {TM }}$ plate). (XLSX 67 kb)

\section{Abbreviations}

Bcr-Abl: Breakpoint cluster region Abelson murine leukemia viral oncogene homologue 1; BrdU: Bromodeoxyuridine-assay; DF: Dilution factor; DMEM: Dulbecco's Modified Eagle's Medium; EC: Endothelial cell; ECBM: Endothelial Cell Basal Medium; ECGM: Endothelial Cell Growth Medium; ELISA: Enzyme-linked Immunosorbent Assay; FCS: Fetal Calf Serum; GHP: German Homeopathic Pharmacopoeia; H. niger: Helleborus niger L., black hellebore, christmas rose; HMPC: Committee on Herbal Medicinal Products; HNE: Helleborus niger aqueous fermented extract; HPLC-DAD: High pressure liquid chromatography with diode array detection; HUVEC: Human Umbilical Vein Endothelial Cells; ISO: International Organization for Standardization; OD: Optical density; OECD: Organisation for Economic Cooperation and Development; ROI: Regions of interest; RPMI-1640: Rosewell Park Memorial Institute; S9: Supernatant 9000 x g; SD: Standard deviation; SRc: Cellular sarcoma; VEGF-A: Vascular Endothelial Growth Factor A; WST-1: Water Soluble Tetrazolium-assay

\section{Acknowledgements}

We thank BSL Bioservice Scientific Laboratories GmbH (Planegg, Germany) and Harlan CCR (Rossdorf, Germany) for conducting the safety assessments, as well as ProQinase GmbH (Freiburg, Germany) and HeidelbergPharma $\mathrm{GmbH}$ (Heidelberg, Germany) for performing the in vitro assays to assess the therapeutic potential. J. Bertrams and E. Ziglgänsberger drom WALA Heilmittel $\mathrm{GmbH}$ are acknowledged for conducting HPLC analysis of HNE extracts.

\section{Funding}

This research did not receive any specific grant from funding agencies in the public, commercial, or not-for-profit sectors.

\section{Availability of data and materials}

The datasets used and/or analyzed during the current study are available from the corresponding author on reasonable request.

\section{Authors' contributions \\ JF analyzed and interpreted the data regarding the investigations of angiogenesis, tube formation, proliferation and migration. CT analyzed and interpreted the data regarding hemolysis and Ames test. AH supported the analysis of the hemolysis investigation. NM supervised the safety assessment. MM provided the test items and the analytical information about the test items. FS supervised, read and corrected earlier versions of the manuscript. All authors read and approved the final manuscript.}

Authors' information

"Not applicable" for that section.

Ethics approval and consent to participate Not applicable.

Consent for publication

Not applicable.

Competing interests

The authors declare that they have no competing interests. 


\section{Publisher's Note}

Springer Nature remains neutral with regard to jurisdictional claims in published maps and institutional affiliations.

\section{Author details}

${ }^{1}$ Pharmacological and Clinical Research, WALA Heilmittel GmbH, Dorfstr. 1, 73087 Bad Boll, Eckwälden, Germany. ${ }^{2}$ Drug Safety/Information, WALA Heilmittel GmbH, Dorfstr. 1, 73087 Bad Boll, Eckwälden, Germany. ${ }^{3}$ Analytical Development \& Research, WALA Heilmittel GmbH, Dorfstr. 1, 73087 Bad Boll, Eckwälden, Germany.

Received: 2 November 2018 Accepted: 2 May 2019

Published online: 21 May 2019

\section{References}

1. Maior MC, Dobrotă C. Natural compounds with important medical potential found in Helleborus sp. Cent Eur J Biol. 2013;8:272.

2. Stintzing F, Selinger $E$, Lindequist U. Helleborus niger - Inhaltsstoffe, In-vitroAktivität und Herstellung von WALA-Arzneimitteln. J Anthro Med. 2010;63: 567-73

3. Wilkens J. Die Heilkraft der Christrose. Aarau und München: AT Verlag; 2014.

4. Duckstein SM, Stintzing FC. LC-MSn characterization of steroidal saponins in Helleborus niger L. roots and their conversion products during fermentation. Steroids. 2015:93:47-59.

5. Schlodder D. Neuentdeckung einer bedeutenden Heilpflanze: Die Christrose (Helleborus niger L.), Teil I. J Anthr Med. 2006;59:541-5.

6. Jesse P, Mottke G, Eberle J, Seifert G, Henze G, Prokop A. Apoptosis-inducing activity of Helleborus niger in ALL and AML. Pediatr Blood Cancer. 2009;52:464-9.

7. Duckstein SM, Stintzing FC. Comprehensive study of the phenolics and saponins from Helleborus niger L. leaves and stems by liquid chromatography/ tandem mass spectrometry. Chem Biodivers. 2014;11:276-98.

8. Duckstein SM, Lorenz P, Conrad J, Stintzing FC. Tandem mass spectrometric characterization of acetylated polyhydroxy hellebosaponins, the principal steroid saponins in Helleborus niger L. roots. Rapid Commun Mass Spectrom. 2014;28:1801-12.

9. Dinan L. Phytoecdysteroids: biological aspects. Phytochemistry. 2001;57: 325-39.

10. Havsteen $\mathrm{BH}$. The biochemistry and medical significance of the flavonoids. Pharmacol Ther. 2002;96:67-202.

11. Böttger S, Hofmann K, Melzig MF. Saponins can perturb biologic membranes and reduce the surface tension of aqueous solutions: a correlation? Bioorg Med Chem. 2012;20:2822.

12. Martin ML, San Romàn L, Dominguez A. In vitro activity of protoanemonin, an antifungal agent. Planta Med. 1990;56:66-9.

13. Wink M, Schimmer O. Functions and biotechnology of plant secondary metabolites. In: Wink M, editor. Annual plant reviews 39. Oxford: WileyBlackwell; 2009. p. 21-161.

14. Büssing A, Schweizer K. Effects of a phytopreparation from Helleborus niger on immunocompetent cells in vitro. J Ethnopharmacol. 1998;59:139-46.

15. Minakata $\mathrm{H}$, Komura $\mathrm{H}$, Nakanishi K, Kada T. Protoanemonin, an antimutagen isolated from plants. Mutat Res. 1983;116:317-22.

16. Teuscher E, Lindequist U. Biogene Gifte. Biologie - Chemie - Pharmakologie - Toxikologie. Protoanemonin als Giftstoff der Hahnenfußgewächse, 3rd ed. Stuttgart: Wissenschaftliche Verlagsgesellschaft; 2010. p. 31-32.

17. Habermehl G, Ziemer P. Mitteleuropäische Giftpflanzen und ihre Wirkstoffe. Helleborus niger L., Schwarze Nießwurz, Christrose, 2nd ed. Berlin, Heidelberg, New York: Springer-Verlag; 1999. p. 75-76.

18. Wolf HU. Helleborin, Helleborus niger L., Hellebrin. In: Wolf HU, editor. Hagers Handbuch der pharmazeutischen Praxis. Gifte, 5th ed. Berlin, Heidelberg, New York: Springer-Verlag; 1992. p. 650-4.

19. Sticher O. Saponine. In: Hänsel R, Sticher O, editors. Pharmakognosie Phytopharmazie. 8th ed. Heidelberg: Springer Medizin Verlag; 2007. p. 943-51.

20. GHP. Regulation no. 34c. In: Medpharm scientific publishers, German homeopathic pharmacopoeia. Stuttgart: Wissenschaftliche Verlagsgesellschaft; 2015

21. Schink M, Carcia-Käufer M, Bertrams J, Duckstein SM, Müller MB, Huber R, et al. Differential cytotoxic properties of Helleborus niger $L$. on tumour and immunocompetent cells. J Ethnopharmacol. 2015;159:129-36.

22. OECD. Test no. 471: bacterial reverse mutation test. Paris: OECD Publishing: 1997. https://doi.org/10.1787/9789264071247.
23. Ames BN, Durston WE, Yamasaki E. Carcinogens are mutagens: a simple test system combining liver homogenates for activation and bacteria for detection. Proc Natl Acad Sci U S A. 1973;70:2281-5.

24. Ponce $L$, Section IV. In vitro techniques. Chapter 10: tube formation: an in vitro matrigel angiogenesis assay. In: Martin S, Murray C, editors. Methods in molecular biology, angiogenesis protocols. 2nd ed. New York: Humana Press; 2009. p. 183-8.

25. Korff T, Augustin HG. Tensional forces in fibrillar extracellular matrices control directional capillary sprouting. J Cell Sci. 1999;112:3249-58.

26. Korff T, Augustin HG. Integration of endothelial cells in multicellular spheroids prevents apoptosis and induces differentiation. J Cell Biol. 1998;143:1341-52.

27. HMPC. Guideline on the assessment of genotoxicity of herbal substances/ preparations. Doc. Ref. EMEA/HMPC/107079/2007. London: European Medicines Agency (EMEA); 2008. p. 1-12.

28. Kirkland D, Aardema M, Henderson L. Evaluation of the ability of a battery of three in vitro genotoxicity tests to discriminate rodent carcinogens and non-carcinogens I. sensitivity, specificity and relative predictivity. Mutat Res. 2005;584:1-256

29. Schrenk D, Merz KH, Jochims K. Feasability study of nonclinical safety assessment on homeopathic preparations using the example of protoanemonin in Pulsatilla pratensis L. Regul Toxicol Pharmacol. 2013;66:104-8.

30. Folkman J. Tumor angiogenesis therapeutic implications. N Engl J Med. 1971;285:1182-6.

31. Holmgren L, O'Reilly MS, Folkman J. Dormancy of micrometastases: balance proliferation and apoptosis in the presence of angiogenesis suppression. Nat Med. 1995;1:149-53.

\section{Ready to submit your research? Choose BMC and benefit from:}

- fast, convenient online submission

- thorough peer review by experienced researchers in your field

- rapid publication on acceptance

- support for research data, including large and complex data types

- gold Open Access which fosters wider collaboration and increased citations

- maximum visibility for your research: over $100 \mathrm{M}$ website views per year

At BMC, research is always in progress.

Learn more biomedcentral.com/submissions 